\title{
Circo e ginástica em folhas de papel: o pequeno tratado de acrobacia e gymnastica
}

\section{Circus and gymnastics on paper sheets: the small treatise of acrobatics and gymnastics}

\author{
Daniel de Lopes* \\ Mônica Caldas Ehrenberg* \\ Erminia Silva $^{* *}$
}

\begin{abstract}
RESUMO
Em meio aos entrelaçamentos históricos entre circo e ginástica, temos por objetivo apresentar e realizar análises referentes a até então obra inédita intitulada "Pequeno Tratado de Acrobacia e Gymnastica", escrita pelo circense Raul Olimecha na década de 1920. Nesse sentido, evidenciamos o quanto essa publicação se constituiu como uma produção que revela os saberes dos circenses sobre o corpo e sobre a ginástica, uma vez que seu objetivo é tanto o ensino das práticas e modalidades circenses como também o de atender o propósito de explicitar as vantagens que oferece o cultivo de uma ginástica educativa tendo por base o artista de circo, classe à qual pertencia Olimecha. Por meio do acesso direto ao Tratado e da sua análise em cruzamento com diferentes fontes de pesquisa, entendemos que a composição e a publicação desse trabalho ampliam ainda mais as perspectivas de análise e debate referentes aos cruzamentos entre o circo, a ginástica e as práticas de educação do corpo no século XIX e início do XX e a compreensão dos circenses como detentores de múltiplos e complexos saberes sobre o corpo, sua arte e seus processos educativos.
\end{abstract}

Palavras-chave: Ginástica. Circo. Corpo. História da educação.

*Universidade de São Paulo. Faculdade de Educação. São Paulo, São Paulo, Brasil. E-mail: territio@gmail.com - https://orcid.org/0000-0002-2137-2060 E-mail: monica.ce@usp.br - https:// orcid.org/0000-0002-2445-1362

${ }^{* *}$ Universidade Estadual de Campinas. Campinas, São Paulo, Brasil. E-mail: mina.silva@ gmail.com - https://orcid.org/0000-0003-3661-1623 


\begin{abstract}
Amidst the historical interlacing between circus and gymnastics, we aim to present and carry out analyzes referring to a previously unpublished work entitled Small Treaty of Acrobatics and Gymnastics, written by circus Raul Olimecha in the 1920s. In this sense, we show how this publication constituted itself as a production that reveals the circus' knowledge about the body and gymnastics since its objective is both the teaching of practices and circus modalities as well as explaining the advantages offered by educational gymnastics cultivation based on the circus artist, the class that Olimecha belonged. Through direct access to the Treaty and its analysis in crossing with different research sources, we understand that this work's composition and publication further expand the analysis perspectives and debate regarding the crossings between circus, gymnastics, and the body education practices in the XIX and early XX centuries and the circuses understanding as having multiple and complex knowledge about the body, its art, and its educational processes.
\end{abstract}

Keywords: Gymnastics. Circus. Body. Education History.

\title{
Introdução
}

Tendo em vista que os circos ao longo do século XIX e XX foram espaços de disseminação de informações, modelos e práticas ginásticas, mesmo diante do questionamento daqueles partidários de uma ideia científica de educação do corpo ligada aos intuitos de disciplina, utilidade e desenvolvimento de hábitos higiênicos (SOARES, 2005; MELO; PERES, 2014), pretendemos apresentar e analisar a obra "Pequeno Tratado de Acrobacia e Gymnastica" escrita pelo circense Raul Olimecha no início do século XX com o intuito de compreender os entrelaçamentos históricos entre circo e ginástica.

No período em questão, os discursos de médicos, de militares e de educadores desconsideravam as práticas circenses como educativas, associandoas apenas ao risco e ao simples espetáculo, e legitimavam a ginástica como prática racional de educação do corpo, de forma a se oporem diretamente ao circo, aos circenses e seus saberes sobre o corpo (SOARES, 2005; GÓIS JUNIOR; HAUFFE, 2014). Nesse sentido, a importância da apresentação e análise da composição da obra Raul Olimecha, proposta por esse artigo, se dá por ela sinalizar o quanto circo e ginástica foram áreas que se misturaram e se influenciaram mutuamente no período e o quanto os circenses eram e são detentores de saberes, técnicas e domínios sobre o corpo mesmo diante dos discursos que os desqualificavam. 
Diante dessa proposta de análise da obra, realizamos também o levantamento, seleção e cruzamento de diferentes fontes (CERTEAU, 2010), constituindo um corpo documental composto por livros, artigos e principalmente nove títulos de periódicos fluminenses e um maranhense que foram consultados na Hemeroteca Digital da Biblioteca Nacional (RJ) e que tratam tanto da elaboração da obra em questão quanto da família Olimecha.

Ao tomarmos por base essas fontes periódicas, evitamos seu uso de forma ingênua e instrumental, como apenas receptáculos e veículos de informações a serem selecionadas e extraídas, ou mesmo como sendo imparciais, neutros ou isolados da realidade política e social na qual se inserem. Evitamos também buscar nessas fontes aquilo que pretendemos confirmar, mas sim interrogá-las por meio de mediações cuidadosas e interpretações críticas (LUCA, 2008). Ademais, utilizamos como palavras-chave para a busca das ocorrências referentes ao Tratado e aos Olimecha, principalmente no acervo da Hemeroteca Digital da Biblioteca Nacional do Rio de Janeiro, os temos Olimecha e Raul Olimecha, orientados pelo o método nominativo sugerido por Ginzburg (1989), que pressupõe o nome dos sujeitos estudados como uma peça inicial para a realização de uma investigação e construção de uma narrativa, visando não a elaboração de suas biografias, mas sim a busca pelos indícios de suas produções, vivências e realizações.

Ao nosso entender, a composição e a publicação do "Pequeno Tratado" ampliam ainda mais as perspectivas de análise e debate referentes aos cruzamentos entre o circo, a ginástica e as práticas de educação do corpo no século XIX e início do XX e a compreensão dos circenses como detentores de múltiplos e complexos saberes corporais significativos para a constituição da educação do corpo gestada no período abordado.

\section{Respeitável público, o pequeno tratado de acrobacia e gymnastica}

Os Olimecha, família de renome nas artes circenses, tem como um de seus precursores na vida artística o japonês Haytaka Torakiste, nascido em Osaka no ano de 1854 e falecido no Brasil em 1918. Considerado o patriarca da família, aos doze anos de idade Torakiste foi para Londres e excursionou pela Europa e América. Posteriormente, adotou o nome Carlo Franco Olimecha e chegou ao Brasil em 1888 com o palhaço e empresário circense inglês Frank Brown. Aqui trabalhou com outros destacados artistas do período, como Manuel Pery, Afonso Spinelli, Podestá, Holmer e Sigly, tendo no ano de 1909 montado seu próprio circo, o Circo Olimecha. 
Em excursão pelo Uruguai, Carlo Franco se casou com Julia Rossi Olimecha e o casal teve oito filhos (DIÁRIO DE NOTÍCIAS, 1932). Dentre eles, destacou-se Raul Olimecha, nascido em São Luiz, Maranhão, em 16 de junho de 1902 (DIÁRIO DO MARANHÃO, 1902), possivelmente no Circo Pery, de propriedade de Manuel Pery, que estava na capital maranhense nesse período. Além de ter sido "acrobata-saltador" (MUNDO ILUSTRADO, 1958, p. 57), Raul era considerado como uma "espécie de literato da família" (REVISTA DA SEMANA, 1947, p. 6).

Desta inclinação para as letras, que se caracterizou pelas produções de peças, músicas e poesias por parte de Raul, atividades comumente desenvolvidas por diversos circenses, nos chama a atenção e nos é muito caro analisar o fato do artista também ter escrito um "Manual de Acrobacia Circenses" (MUNDO ILUSTRADO, 1958, p. 57).

A versão do Tratado de Raul Olimecha a qual tivemos pleno acesso está encadernada juntamente com um livreto intitulado "Normas para a Instrução de Saltos e Acrobacias Elementares", do Departamento de Educação Física da Escola da Aeronáutica do Rio de Janeiro, publicado em junho de 1945, e consta no acervo do ator, pesquisador e militante das artes João Angelo Labanca (19131988), pertencente ao Centro de Documentação e Informação da Fundação Nacional de Artes (CEDOC/FUNARTE - RJ). A encadernação dessas duas obras em conjunto, uma vez que são publicações individuais, realizadas por diferentes editoras e em períodos distintos, possivelmente foi realizada por Labanca em função da afinidade dos temas que abordam.

Apesar do falecimento de Raul Olimecha em 1930, “O Pequeno Tratado de Acrobacia e Gymnastica" foi publicado em 1933 pelos irmãos Olimecha por meio das "Officinas Graphicas Instituto Commercial, Rua 13 de maio, 64, Campos, Rio de Janeiro", no entanto, não se colocam como autores da obra, sendo a autoria, portanto, de exclusividade de Raul Olimecha. 
FIGURA 1 - CAPA DO "PEQUENO TRATO DE ACROBACIA E GYMNASTICA".

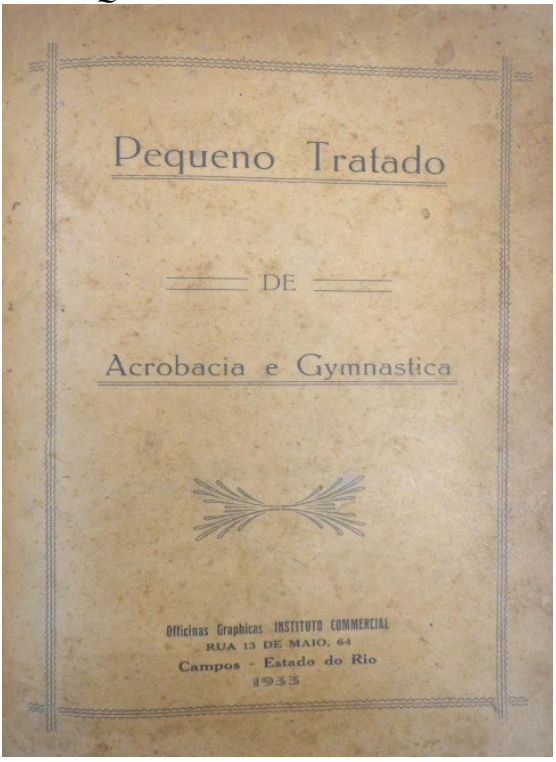

FONTE: CEDOC/FUNARTE, 2020.

Imediatamente após a capa, a obra é ilustrada com uma foto de Raul Olimecha e, em seguida, apresenta uma nota de abertura escrita pelos irmãos Olimecha intitulada "Aos que nos lerem", em homenagem póstuma à Raul e com explicações prévias sobre o trabalho. Dessas explicações, temos que o Tratado foi escrito em 1924 e "coordenado segundo as instruções do autor de um compendio acrobático, Prof. Zecchi" e, ainda, um alerta a respeito da dificuldade de se escrever sobre a "arte acrobática no Brasil e a sua evolução, assunto ainda não tratado por escritor algum”.

Cabe destacar que posteriormente o mesmo professor será mencionado novamente no livro, mas com seu nome grafado como "prof. A. Zucca". Tomando por base essa grafia, é possível afirmar que esse educador trata-se de Alberto Zucca, professor italiano de ginástica nas Escolas Normal e Governamental do Reino que em 1902 escreveu em Milão o livro “Acrobatica e Atletica”, dedicado diretamente ao ensino de modalidades circenses e às dinastias de circo na Itália.

$\mathrm{Na}$ sequência, o prefácio é apresentado, escrito pelo circense Francisco Colman (1933), que em linhas gerais elogia Raul por sua inciativa; refere-se à família Olimecha e sua importância no universo circense; critica pessoas que não nasceram no circo e que passaram a trabalhar com essa arte, chamadas por ele 
de "aventureiros" e, em especial, afirma que "Não consta nos anais da história do circo (afirmo sem medo de errar) quem deixasse memórias escritas que fossem o cosmorama perfeito do que se tem visto relativamente a Gymnastica e Acrobacia, Saltos e Equitação, propriamente cultivados em circo. Neste ponto o Sr. Olimecha aparece unicamente só" (COLMAN, 1933).

Quanto a essa afirmação de Colman, é importante levantar a ressalva de que, possivelmente, no Brasil, o trabalho de Raul seja único, pois não encontramos evidências de outras publicações semelhantes em língua portuguesa antes da década de 1930. No entanto, na Europa já existiam publicações similares, a exemplo da já citada obra italiana "Acrobatica e Atletica" (1902), de Alberto Zucca, e das obras francesas "Les jeux du cirque et la vie foraine", de Hugues Le Roux, de 1889; "L'Acrobatie et les acobates", de G. Strehly, de 1903, e "Le Cirque, L'Equitation et L'Athletisme", escrita por E. Molier e publicada em 1925.

Vale mencionar que Francisco Colman (1899-1980) era filho de circenses e foi acrobata, ator, diretor e literato, tendo editado jornais e revistas e publicado poesias, crônicas e adaptado fitas de cinema e peças de teatro para o circo-teatro. Foi professor e secretário, na década de 1920, no Circo Nerino (TAMAOKI, 2007) e em 1976 coordenou a fundação da Associação Piolim de Artes Circenses, que resultou na fundação da Academia Piolim de Artes Circenses, inaugurada em 1978 em São Paulo.

Retornando ao conteúdo e organização do "Pequeno Tratado de Acrobacia e Gymnastica", após seu prefácio temos uma nota do próprio Raul Olimecha em que ele reforça o caráter da obra como uma "exegese superficial da arte que cultivo com amor e carinho" e que, ainda, informa que "nas páginas seguintes, empreguei o meu cadastro de truques acrobáticos que executo, baseandose nas opiniões do prof. A. Zucca, com o sincero intuito de tornar claras e compreensíveis as minhas explanações relativas a arte circense".

Apesar do Tratado não dispor de um sumário, seus conteúdos práticos estão organizados da seguinte maneira: "Acrobatas de Ombro" (1933, p. 14), "Báscula ou Balança" (1933, p. 15), "Gymnastica" (1933, p. 16), "Equilibristas" (1933, p. 19), "Malabaristas, antipodistas (equilibristas de pé) e ciclistas" (1933, p. 23), "Contorcionistas" (1933, p. 26), "Equestres acrobatas" (1933, p. 28), “Atletismo" (1933, p. 31) e Gymnastica Sueca (1933, p. 32).

Essa organização da obra possibilita visualizar a amplitude de temas que foram abordados, sendo que o autor apresenta um espectro de modalidades circenses (equilibrismo, acrobacia, contorcionismo, malabarismo etc.) e as organiza em conjunto com temas/práticas como "Athletismo" (1933, p. 31) e "Gymnastica Sueca" (1933, p. 32), o que indica previamente a fusão e mistura deles por parte de Raul. No entanto, antes de abordamos mais especificamente essas misturas e o tratamento, sentidos e intencionalidades dadas pelo autor da 
obra quanto à ideia de "Gymnastica" (1933, p. 16), "Athletismo" (1933, p. 31), "Gymnastica Sueca" (1933, p. 32) etc., vale ressaltar que todo o seu trabalho é realmente adornado com ilustrações ou "desenhos esplendidamente educativos", conforme a nota publicada no jornal Diário da Noite (1933, p. 4). Quanto a essas ilustrações, é possível considerar que foram feitas por Raul Olimecha, uma vez que o circense era empenhado em várias outras expressões artísticas - "uma alma sensível às elevadas manifestações de arte" (DIÁRIO DA NOITE, 1930, p. 5) -, e que foram feitas inspiradas diretamente no livro "Acrobatica e Atletica", de Alberto Zucca (1902), uma vez que são extremamente semelhantes.

FIGURA 2 - ILUSTRAÇÕES DE DIVERSAS MODALIDADES CIRCENSES, ACROBÁTICAS E GINÁSTICAS APRESENTADAS NO PEQUENO TRATADO DE ACROBACIA E GYMNASTICA, 1933.
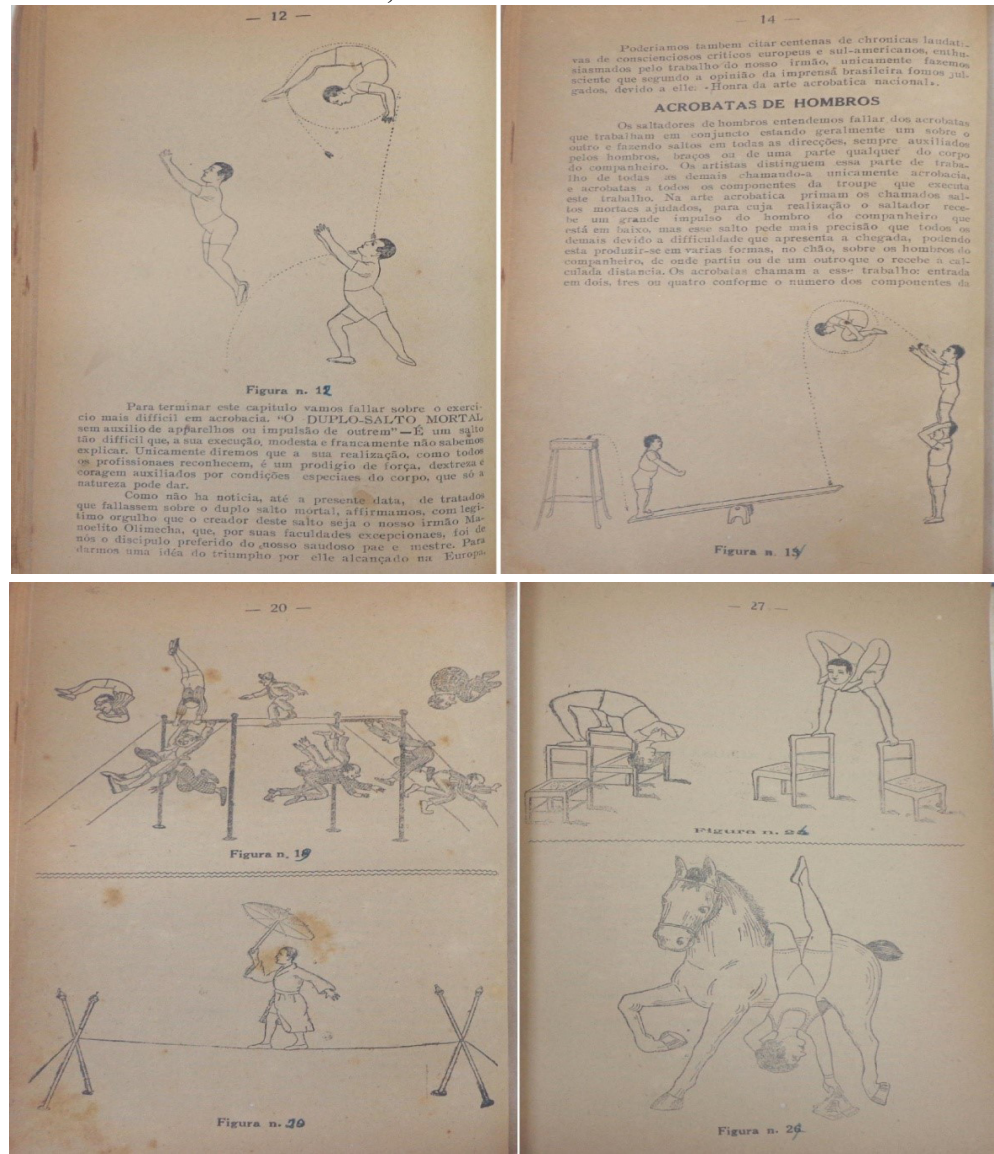


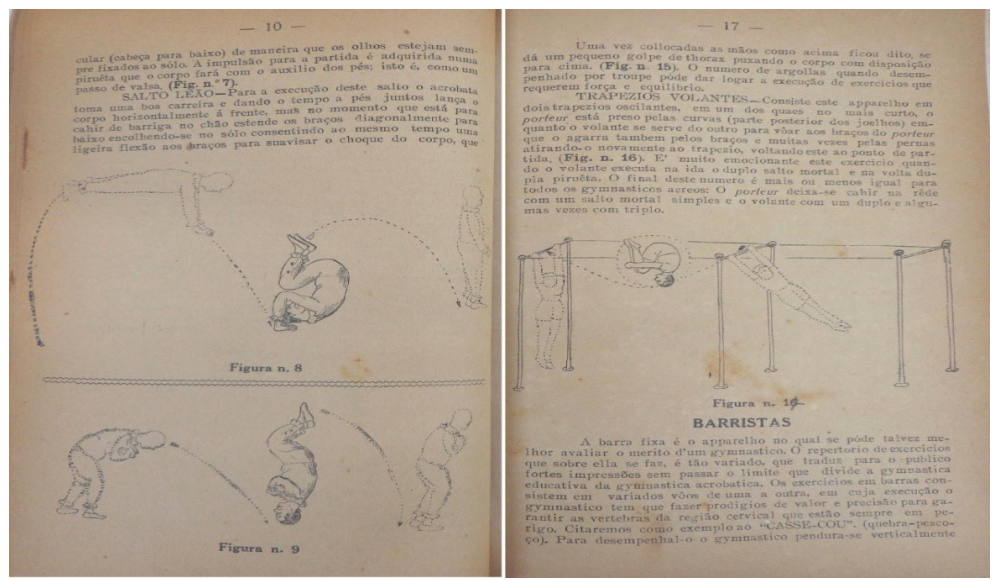

FONTE: CEDOC/FUNARTE, 2020.

Por meio da análise dessas ilustrações, é possível verificar o empenho do autor em detalhar a execução de variados números circenses e exercícios acrobáticos de forma didática, pontuando em minúcias as posturas, direções e giros dos movimentos corporais abordados. As setas e pontilhados que compõem as imagens indicam a orientação e sentido dos deslocamentos e conferem a eles fluidez e dinâmica. Vale salientar também a representação dos corpos desenhados por meio de linhas pontilhadas, que em alguns casos demonstram as fases de partida e chegada dos exercícios e, em outros, as fases de transição que o corpo descreve ao longo dos movimentos, a exemplo do "salto atrás e à frente" apresentado na página 11 da obra, um verdadeiro processo pedagógico dos exercícios e suas evoluções sistemáticas. Somando a essas considerações, chama a atenção o fato de Raul ilustrar com precisão e aprofundamento também os aparelhos nos quais são realizados os números e exercícios, como é o caso das barras, arames, cadeiras e mesmo do cavalo, referente ao número de volteio equestre.

Juntamente com as ilustrações, Raul discorre sobre diferentes números circenses pertencentes às modalidades de malabarismo, contorcionismo, equilibrismo, acrobacia equestre e acrobacias em geral, a exemplo dos números de báscula, percha, antipodismo, ciclismo e atirador de facas. Ao descrevê-los, trata com detalhes das respectivas execuções e aparelhos envolvidos, utiliza nomenclaturas específicas, aborda aspectos técnicos e motores, traça também considerações referentes à segurança e faixa etária adequada para se iniciar em alguns números (como no caso das acrobacias, acrobacias de ombro e 
báscula) e, em muitos casos, apresenta considerações anatômicas como, por exemplo, que "para a execução do salto mortal para a frente concorrem todos os músculos extensores das articulações tíbio-társea, da rotula, coxo femural e mais fortemente os do quadril" (OLIMECHA, 1933, p. 9), e que:

A coluna vertebral tem quatro curvas: uma superior no pescoço chamada cervical que permite flexões a frente e a traz; uma dorsal torácica que consente pouca flexibilidade em ambas as direções, porque o movimento das doze vértebras que a compõem são limitados à frente pelas costelas e atrás pelas apófises espinhosas; uma lombar, correspondendo ao abdômen, que permite adiante só no endireitar-se e concede no sentido posterior uma flexibilidade maior [...]" (OLIMECHA, 1933, p. 26).

Associadas a essas análises e observações que traçamos, o autor, no trecho intitulado "Peripécias da Vida Artística - vida e costume dos artistas", também expõem interessantes considerações pedagógicas apontando que:

A maior parte dos acrobatas tem sempre consigo pequenos discípulos para iniciá-los na sua carreira; irmão, filhos ou meninos confiados à sua responsabilidade. Temos tido ocasião de assistir aos ensaios de artistas formados com seus respectivos discípulos e lamentamos a exagerada severidade com que são tratados estes. A agilidade dos membros, a força dos músculos e o valor, tudo isso pode adquirir-se sem a necessidade de torturar o corpo e sim com um exercício constante e bem determinado, segundo o systema de trabalho a que se dedicar o discípulo.

A experiência sobre si mesmo, pode muito bem servir de guia para a educação physica do aprendiz (OLIMECHA, 1933, p. 2).

Por meio dessa citação, identificamos uma preocupação pedagógica referente ao tratamento e a forma de ensino do corpo, em que o autor valoriza a constância e boa aplicação de exercícios para a preparação corporal do artista segundo um "systema de trabalho" em oposição à perspectiva de um ensino severo. Ainda que a afirmação de Raul soe como uma crítica ao modo como os próprios circenses ensinavam seus discípulos em função da "severidade com que são tratados" - severidade essa presente não somente no circo, mas também nas escolas, lares e nos mais variados espaços de ensino no período -, o que para nós é importante destacar é sua inclinação para uma forma de aquisição de 
agilidade, força muscular e valores pautada por um método de trabalho, coisa que os circenses sempre tiverem apesar das constantes críticas que sofriam de pedagogos, médicos e educadores (SILVA, 2009).

Nesse sentido, para além da sua preocupação pedagógica quanto ao tratamento e a forma de ensino do corpo, seu próprio Tratado é composto por um cuidado pedagógico com os temas que aborda em função das descrições e análises detalhadas das modalidades e números circenses; da amplitude de assuntos que são apresentados; da utilização de diversas imagens explicativas; das menções à faixa etária e a aspectos de segurança e, também, de suas considerações anatômicas.

Após essas reflexões de ordem mais geral, retomemos a parte inicial da obra, mais especificamente o "Preâmbulo", em que Olimecha apresenta o conceito de acrobacia, sua história, suas variedades de estilos e faz importantes considerações:

Nos tempos modernos a arte de dançar sobre a corda é muito differente da que era outrora; vem modificando-se com seguidas transformações, criando a moderna arte acrobática, com o concurso de novos apparelhos, até a mais aperfeiçoada bycicleta. Essa metamorphose despertou os espíritos lúcidos e adiantados, sugerindo-lhes a formação de escolas, para que fossem ministrados os ensinamentos necessários ao cultivo da acrobacia e excentricidades donde sahiram valentes artistas. O moderno ensino veio proteger a verdadeira gymnastica salutar, dividindo os exercícios em dois campos: o educativo, cujo fim é educar o corpo e o espírito; e o acrobático, que só visa impressionar o público, expondo-se o artista a mil perigos, com o intuito de proporcionar, sempre, novas e fortes emoções.

$\mathrm{O}$ interesse desta publicação é explicar os rápidos progressos da arte acrobática, e fazer ver as vantagens que offerece o cultivo da gymnastica educativa, no sentido da autoridade prática que a humanidade poderia ter, nas várias contingências da vida e para o desenvolvimento muscular. Para chegar ao fim do nosso propósito, tomarmos por base o artista de circo, à cuja classe pertencemos (OLIMECHA, 1933, p. 1).

Partindo dessas considerações de Raul, muitos questionamentos e análises são plausíveis de serem realizadas. Raul afirmou que a transformação que vinha sofrendo a acrobacia, a ponto de gerar a "moderna arte acrobática" (OLIMECHA, 1933, p. 1), propiciou a formação de escolas, de onde saíram vários artistas. Quanto a essas escolas, podemos especular que ele se refere aos diversos ginásios e clubes voltados ao ensino da ginástica que foram criados ao longo do século 
XIX e início do XX, dos quais podemos citar os estabelecimentos dirigidos pelo trapezista Jules Léotard, na França, a partir da década de 1860; pelo artista circense, fisiculturista, sistematizador e professor de ginástica Eugene Sandown, na Inglaterra, a partir de 1897, e mesmo as escolas e clubes fundadas pelo atleta brasileiro, professor de ginástica e circense Zeca Floriano, a partir de 1905, que ofereciam condições para a formação e preparação de artistas. Independente de precisar quais formatos de escolas, formas e propósitos de ensino a que se destinavam, é possível afirmar que Raul sugere uma mistura e fusão entre as práticas ginásticas e o circo ao tratar dessa transformação da arte acrobática e do surgimento de estabelecimentos destinados ao seu ensino.

Em consonância com essa ideia da fusão e mistura desses dois campos para o autor, temos a afirmação de que o "moderno ensino [da acrobacia] veio proteger a verdadeira gymnastica salutar, dividindo os exercícios em dois campos: o educativo, cujo fim é educar o corpo e o espírito; e o acrobático, que só visa impressionar o público, expondo-se o artista a mil perigos, com o intuito de proporcionar, sempre, novas e fortes emoções" (OLIMECHA, 1933, p. 1). Por meio dessa consideração, Raul assume de certa maneira que o campo dos exercícios acrobáticos, que visam ao espetáculo e a estimular os sentidos do público, estão dentro da ideia de uma "verdadeira gymnastica salutar", "protegida" pelo "moderno ensino" (1933, p. 1). No entanto, sua perspectiva é de que o campo dos exercícios acrobáticos, evidentemente ligados às manifestações circenses, mesmo pertencendo a uma "verdadeira gymnastica salutar" não são educativos, pois "só visa impressionar o público" (OLIMECHA, 1933, p. 1), expondo o artista ao perigo e com o propósito de propiciar fortes emoções aos espectadores. Ou seja, parece que Raul ao mesmo tempo que classifica os exercícios do campo acrobático como salutares, os desvaloriza ao suprimir seu sentido educativo.

Apesar disso, não podemos esquecer o fato de que ele era um artista de circo, que trabalhava na perspectiva do risco, do impressionante, e que sua formação foi pautada nos conhecimentos, técnicas e métodos circenses. Ainda, para além desse fato, Raul evidencia que o objetivo de sua publicação é "fazer ver as vantagens que oferece o cultivo da gymnastica educativa, no sentido da autoridade prática que a humanidade poderia ter, nas várias contingencias da vida e para o desenvolvimento muscular" (OLIMECHA, 1933, p. 1), mas para isso toma como referência o seu lugar, ou seja, o circo, sua arte e seus saberes e práticas.

A partir dessas análises, podemos inferir que, mesmo apontando uma não proposta educativa dos exercícios acrobáticos correspondentes ao universo das artes circenses, ele entende o circo, conforme indicamos, como uma prática corporal que integra a ideia de uma "verdadeira gymnastica salutar" 
(OLIMECHA, 1933, p. 1) e o elege como base para tratar em sua obra das vantagens do cultivo da prática da ginástica que ele considera educativa. Posto isso, podemos compreender que, de forma não explícita, Raul acabava por conceber as práticas circenses, consequentemente, como também educativas, pois, como ele mesmo afirmou, "Para chegar ao fim do nosso propósito, tomamos por base o artista de circo, à cuja classe pertencemos" (OLIMECHA, 1933, p. 1). Em outras palavras é possível entender que, se ele toma as práticas e saberes circenses como base para tratar da ideia de uma ginástica educativa, vale a análise de que Raul, de forma menos declarada, concebe os exercícios acrobáticos referentes ao universo das práticas circenses como também detentores de um caráter educativo.

Evidentemente, dessas complexas posições de Olimecha, temos que tanto o seu Tratado como ele próprio, como artista que discorreu e publicou seus saberes sobre o corpo e sua arte, estabeleceu e representou diretamente um intenso entrelaçamento entre circo e ginástica, indicando que seu modo de pensar, agir e experienciar estava em sintonia com os debates e realizações tanto no campo do circo como no campo da ginástica no período. Nesse sentido, uma de suas considerações apresentadas no Pequeno Tratado explicita claramente essa profunda mistura, uma vez que Raul classifica o volteio sobre o cavalo como pertence à "gymnastica educativa", mas que considera que "o artista que desejar angariar alguns applausos do público, não pode limitar-se ao simples volteio, terá que entrar à acrobacia e por isso executar trucs diffíceis enquanto o cavallo salta obstáculos" (OLIMECHA, 1933, p. 28). Dessa forma, para Raul, os limites entre as práticas ginásticas e as representações circenses eram extremamente tênues e suas práticas, exercícios e números estavam permanentemente emaranhados.

Aliado a esse debate que temos apresentado, é importante destacar que Raul nomeia um dos tópicos do seu trabalho de "Gymnastica", que se encontra mais precisamente na página 16. Apesar de já ter apresentado diversas modalidades e exercícios acrobáticos, é somente nesse momento que utiliza a expressão ginástica. A razão para isso provavelmente se deve ao fato de Raul compreender a ideia de ginástica como sinônimo de exercícios realizados em aparelhos específicos, pois ele inicia esse tópico sem conceituar ou explicar a compreensão que possui sobre a ideia de ginástica, mas sim descrevendo as modalidades de "Argolas ou Anéis", "trapézios volantes" e "Barra fixa" como práticas e números circenses pertencentes a esse campo.

Essa abordagem de Raul converge com o fato de que os aparelhos pertencentes a essas modalidades, bem como os exercícios e ações físicas realizadas sobre eles estavam amplamente presentes nos circos mas também nas aulas de ginásticas em clubes, ginásios e escolas no Brasil e na Europa e em diferentes períodos, e que comumente ginastas e circenses denominavam 
os exercícios e evoluções realizadas sobre eles pelo termo ginástica (ROMÃO, 2016; LOPES, 2020).

Nesse sentido, o apontamento que Olimecha faz, mais especificamente a respeito do aparelho "Barra fixa", esclarece de certa maneira sua compreensão de ginástica e seu entrelaçamento com o universo do circo:

O repertório de exercícios que sobre ella se faz é tão variado, que traduz para o público fortes impressões sem passar o limite que divide a gymnastica educativa da gymnastica acrobática. Os exercícios em barras consistem em variados voos de uma a outra, em cuja execução o gymnastico tem que fazer prodígios de valor e precisão para garantir as vértebras da região cervical que estão sempre em perigo (OLIMECHA, 1933, p. 17).

Assim, por meio dessa citação, Raul explicita que a "Barra fixa" é um aparelho que está inserido tanto no campo da ginástica quanto do circo, como também evidencia que sua prática não distingue bem a fronteira do que ele compreende por "gymnastica educativa" e "gymnastica acrobática", uma vez que os variados exercícios realizados nesse aparelho causam no público as "fortes impressões" dos números e apresentações circenses.

Ainda, de forma a complexificar mais as representações de Raul Olimecha sobre circo, corpo e ginástica, temos que ele encerra sua obra com um tópico intitulado "Gymnastica Sueca":

\section{GYMNASTICA SUECA}

Para o cultivo dessa gymnastica, aconselhamos a leitura de um trabalho escripto pelo grande educador physico Enéas Campello, e dos apparelhos inventados pelo célebre artista e professor de gymnastica geral "Sandow", o qual foi considerado durante muitos annos o corpo mais physicamente perfeito do Mundo.

Terminamos o nosso livro aconselhando o cultivo da gymnastica sueca, como o melhor para accentuar a belleza pessoal e a galhardia dos músculos. A gymnastica geral foi, é, e será em todos os tempos, o melhor meio para a preparação de úteis cidadãos e valentes soldados.

“MENS SANA IN CORPORE SANO" (OLIMECHA, 1933, p. 32). 
Claramente, Raul, ao recomendar a prática da ginástica sueca, evidencia possuir conhecimento de seus métodos e preceitos, ainda mais que nesse período havia a circulação de impressos sobre a ginástica sueca em língua portuguesa (MORENO; 2015; BAIA, BONIFACIO; MORENO, 2017). Ademais, por meio dessa citação que encerra seu Tratado, podemos identificar o claro diálogo que estabelece com o pensamento normativo pedagógico e médico higienista que subsidiava a ginástica no período ao evidenciar a ideia da ginástica como "o melhor para a preparação de úteis cidadãos e valentes soldados" e destacar o bordão de "uma mente sã num corpo são". Vale, ainda, destacar a indicação que faz do trabalho de Enéas Campello e dos aparelhos inventados por Eugene Sandow, duas personalidades que merecem destaque.

Eugene Sandow foi o nome artístico adotado por Friederich Wilhelm Müller (1867-1925), artista e fisiculturista que nasceu na Prússia e destinou sua vida ao trabalho, desenvolvimento e exibição de força muscular. Em 1885, Sandow passou a trabalhar como acrobata circense e a dedicar-se intensamente ao treinamento muscular, sendo que ao longo de sua carreira como fisiculturista realizou apresentações e "exibições de músculo" em diversos circos e espetáculos de variedades na Europa e nos Estados Unidos, nas quais realizava tanto poses físicas diversas quanto façanhas de força, como arrebentar correntes com seus músculos. A partir de 1897, fundou diversos institutos de cultura física voltados para o treino e desenvolvimento muscular e, em 1898, passou a publicar diversos periódicos e livros nos quais apresentava e discutia seus métodos de treinamento. Nesse mesmo período, Sandow criou, adaptou e aperfeiçoou aparelhos para musculação, idealizou e realizou competições de fisiculturismo. Devido à sua trajetória, segundo Chapman (1994), é considerado como pai da musculação e criador do fisiculturismo.

Quanto ao "trabalho escripto" por Enéas Campello, julgamos importante em vista da análise e compreensão da obra de Raul Olimecha abrirmos espaço para tratarmos de sua atuação no campo dos esportes, do espetáculo e da educação do corpo.

Enéas Campello Bastos, nascido em 2 de agosto de 1881, era cearense e foi um importante atleta de variadas modalidades, acrobata, lutador, massagista, inventor de aparelhos de ginástica, professor de ginástica sueca em estabelecimentos particulares, no colégio Batista, no Ginásio Brasileiro e no Colégio Militar, no Rio de Janeiro, no começo do século XX (LOPES, 2020).

Campello, em suas realizações no campo do circo, do esporte e da ginástica, atuou em parceria com o também artista e sportsman Zeca Floriano e estiveram concorrendo juntos em diversas competições e eventos esportivos, a exemplo de um "Campeonato de Força", que consistia no levantamento de pesos, realizado em 26 de dezembro de 1906 (GAZETA DE NOTÍCIAS, 1906, 
p. 4) e, no ano de 1909, competiram nas modalidades de "Acrobacia em geral e gymnastica", num "festejo sportivo" denominado "Exposição de Hygiene", de inciativa do "sindicato americano" (CORREIO DA MANHÃ, 1909, p. 5). Segundo reportagem publicada no $O$ Globo Esportivo, de 18 de novembro de 1939, Campello e Floriano "Eram os Tarzan da época [...]. Toda a cidade os conhecia, toda a cidade falava-lhes nos músculos de aço em contraste da palidez que predominava nos salões [...]" (O GLOBO ESPORTIVO, 1939, p. 20).

Juntos, fundaram o "Centro de Cultura Physica Enéas Campello", que por décadas organizou festejos, celebrações esportivas, provas de resistência física e disputas de luta Romana, além de oferecer aulas de ginástica sueca, pirâmides e luta romana (GAZETA DE NOTÍCIAS, 1915, p. 7). Em uma das propagandas de divulgação do Centro, é possível identificar que oferecia a prática de "exercícios physicos" por meio de "processos methodicos" a homens e meninos, e um "gabinete de massagem". Ainda, o Centro vendia pesos, aparelhos de ginástica, regras para a prática dos exercícios e "tabelas práticas de gymnastica sueca", além de confeccionar aparelhos de exercícios físicos sob encomenda, idealizados por Enéas Campello (GAZETA DE NOTÍCIAS, 1916, p. 10).

Conforme indicam as fontes apresentadas, Campello ensinava e praticava a ginástica sueca segundo "tabelas práticas" e "processos methodicos" e, de acordo com uma nota publicada na revista "O Tico Tico" datada 31 de julho de 1918 (TICO TICO, 1918, p. 18), escreveu um livro dedicado ao seu ensino: "Procure na Casa Stamp, à rua Uruguaiana, o livro que Enéas Campello fez público contendo todas as especificações e posições para a prática da útil Gymnastica Sueca. É o melhor que a respeito conhecemos". Essa publicação, também denominada de "Método de Cultura Physica de Enéas Campello" (A NOITE, 1940, p. 2), possivelmente é a obra da qual se refere e recomenda Raul Olimecha no fim de seu Tratado.

É importante apontar que Enéas Campello esteve também intimamente ligado ao campo dos espetáculos e, em especial, aos circenses. Dentre suas várias atuações em circos, podemos citar a ocorrida em 1910, em que Circo Spinelli promoveu como forma de espetáculo um "Grande Festival Artístico" dedicado ao "brioso Centro de Cultura Physica" e em homenagem ao "simpático professor Enéas Campello, muito digno director que nos honrará com sua presença" (GAZETA DE NOTÍCIAS, 1910, p. 8). Além desta, em 1912, juntamente com seu Centro de Cultura Física, organizou toda a programação de uma grande matinê realizada no próprio picadeiro do circo Spinelli em benefício do Asilo de Santo Antônio (JORNAL DO COMÉRCIO, 1912).

Após esse destaque sobre Enéas Campello, retomemos, então, o tópico final do Tratado de Olimecha. Em função de Raul finalizar seu trabalho recomendando o cultivo da Ginástica Sueca como forma de aquisição de "belleza pessoal e 
galhardia dos músculos" e a prática da ginástica em geral como o "melhor meio para a preparação de úteis cidadãos e valentes soldados", bem como por fazer a indicação das produções de Campello e Sandow, destacamos mais uma vez o quanto a fusão e mistura entre as práticas e saberes circenses e a ginástica estavam amalgamadas tanto em seu Tratado como na sua forma de compreender essas duas áreas.

\section{Considerações finais: 0 fechar das cortinas}

Por meio do Tratado, é possível afirmar que Raul demonstrava possuir conhecimento dos vários discursos que sondavam as artes do picadeiro, que desconsideravam as práticas circenses como educativas, associava-as ao risco e ao simples espetáculo e legitimavam a ginástica como prática racional de educação do corpo (SOARES, 2005; GÓIS JUNIOR e HAUFFE, 2014; LOPES, 2020), uma vez que ele faz a recomendação da Ginástica Sueca como método de preparação de cidadãos úteis e soldados valentes, perspectiva essa presente também nas bases da ginástica francesa de Francisco Amoros, que visava utilidade dos exercícios ginásticos para a formação de cidadãos aptos para o trabalho e para o serviço militar. No entanto, ao mesmo tempo que demonstra conhecer esses discursos vigentes de valorização da ginástica e da negação do circo, Raul assume e destaca as práticas e saberes circenses como suporte de seu Tratado para "fazer ver as vantagens que oferece o cultivo da gymnastica educativa, no sentido da autoridade prática que a humanidade poderia ter, nas várias contingências da vida e para o desenvolvimento muscular" (OLIMECHA, 1933, p. 1).

Aliado a isso, Olimecha também não apresenta de maneira clara as fronteiras entre o que considera "exercícios educativos", voltados para "educar o corpo e o espírito", e o que considera "exercícios acrobáticos", que visavam o efeito espetacular, ou seja, entre a ginástica, seus ideais e o circo. Pelo contrário, admite ambas as formas de exercícios como pertencentes a uma "verdadeira gymnastica salutar" e, evidentemente, conforme apontamos, em vários momentos de seu livro promove permanentemente a mistura entre eles, além do fato de que, se considerarmos que ele toma o circo como base para alcançar o objetivo de divulgar as vantagens da ginástica educativa, indiretamente e consequentemente ele também estava elegendo o circo e suas práticas como também educativas. 
Se, ainda, olharmos com atenção para os sujeitos aos quais Raul recorre para subsidiar seu trabalho, veremos, para além do fato do autor possuir conhecimento dessas personalidades ligadas ao circo e ao ensino da ginástica e de suas produções, o quanto justamente circo e ginástica frequentemente e de diferentes maneiras estiveram integrados e entrelaçados no período, pois Alberto Zucca era ginasta, professor de ginástica e possivelmente artista circense, já que escreveu um amplo livro sobre as artes circenses; Enéas Campello, atleta, professor de ginástica, lutador, inventor de aparelhos de ginástica e atuante no campo dos espetáculos circenses; e Sandow, artista de circo e fisiculturista que fundou centros de treinamento físico e escreveu métodos e sistematizações de desenvolvimento muscular.

Assim, tomando como referência a produção desses educadores, ginastas e artistas, e diante da compreensão da organização, conteúdos e sentidos do trabalho de Olimecha que apresentamos, podemos considerar que, numa perspectiva mais amplificada, o próprio Tratado de Raul reflete a forma como, em meio a sociedade fluminense, principalmente da segunda metade do século XIX e primeiras décadas do $\mathrm{XX}$, as práticas e representações do circo e da ginástica se constituíam de forma entrelaçada. Ou seja, a intensa mistura entre essas duas áreas apresentadas no Pequeno Tratado está, de certa maneira, em consonância com a realidade do ensino e desenvolvimento da ginástica no período, pautada permanentemente pela influência do circo e seus saberes seja em seu ensino nas escolas e sua execução nos clubes, seja nos centros de cultura física e picadeiros (MELO; PERES, 2014; ROMÃO, 2016; LOPES, 2020).

Compreendemos, também, que o trabalho de Raul se constituiu como uma produção que explicita os saberes dos circenses sobre o corpo e sua arte, uma vez que seu objetivo é tanto o ensino das práticas e modalidades circenses como, também, o de atender o propósito de "fazer ver as vantagens que oferece o cultivo da gymnastica educativa" (OLIMECHA, 1933, p. 1) tendo por base o artista de circo, a classe à qual pertencia Raul Olimecha. Nessa perspectiva, é possível considerar que o "Pequeno Tratado de Acrobacia e Gymnastica" evidencia a afirmação e disputa dos circenses na produção de conhecimento sobre o corpo por meio também do campo das publicações bibliográficas, dominado, à época, pela bibliografia de cunho médico e cientificista referente às práticas ginásticas representada por pareceres, métodos e manuais de higiene e ginástica (SOARES, 2001; GÓIS JUNIOR, 2013; MELO; PERES, 2014; MORENO, 2015; PUCHTA, 2015), além do fato de que o Tratado, possivelmente, seja a primeira obra escrita no Brasil dedicada ao circo e à ginástica, voltada, entre outros pontos, para formação e instrução nesses campos.

Podemos considerar que Olimecha foi, portanto, um sujeito conectado à sua época e, consequentemente, seu modo de pensar e compor sua obra estavam 
em sintonia com os debates e embates da época ligados ao circo e à ginástica. Nesse sentido, há evidências de que por meio de seu Tratado ele acabou por explicitar de certa maneira as tensões e disputas existentes entre as práticas e saberes do circo e ginástica presentes no momento ao abordar, entre outros exemplos, esses dois campos de forma complexa e misturada por meio das ideias de "salutar", "educativo", "acrobático" e "arriscado", compondo, dessa forma, um trabalho que, conforme analisamos, evidencia os entrelaçamentos operados em meio a realidade das práticas circenses e ginásticas na sociedade fluminense da segunda metade do século XIX e primeiras décadas do XX. Vale, ainda, considerar que Raul, como um artista circense que buscou exaltar uma ideia de ginástica educativa tomando por base as práticas circenses, parece propor um diálogo ao querer acessar tanto os artistas de circo como também os ginastas e partidários das práticas ginásticas aplicadas em escolas, clubes e centros de cultura física. Assim, seu Tratado se caracteriza como uma obra que comunica a todos, reflete a trama de debates, conceitos e embates entre as práticas ginásticas e as circenses no período e configura-se como uma publicação conectada a seu tempo. Com isso, evidencia-se a necessidade de pensar a ginástica no decorrer do século XIX e início do XX de forma plural, bem como o quanto os saberes circenses referentes à produção de seus espetáculos, sobre o corpo e a ginástica foram presentes e significativos para a constituição da educação do corpo gestada no período abordado.

\section{REFERÊNCIAS}

A NOITE, Rio de Janeiro, 03 fev. 1940.

BAIA, Anderson Cunha; BONIFÁCIO, Iara Marina dos Anjos; MORENO, Andrea. O tratado pratico de gymnastica de L. C. Kumlien: circulação, transformação e vestígios do método sueco de ginástica na educação dos corpos no Brasil (1895-1955). In: CONGRESSO BRASILEIRO DE HISTÓRIA DA EDUCAÇÃO, 9., 2017, João Pessoa. Anais[...]. João Pessoa: SBHE, 2017. p. 3757-3770. Tema: História da Educação: global, nacional e regional.

CERTEAU, Michel de. A escrita da história. Rio de Janeiro: Forense Universitária, 2010. CHAPMAN, David. Sandow the Magnificent. Eugen Sandow and the beginnings of bodybuilding. Chicago: University of Illinois Press, 1994.

COLMAN, Francisco. Prefácio. In: OLIMECHA, Raul. Pequeno Tratado de Acrobacia e Gymnastica. Campos, RJ: Oficinas Graphicas Instituo Comercial, 1933. 
CORREIO DA MANHÃ, Rio de Janeiro, 29 ago.1909.

DIÁRIO DA NOITE, Rio de Janeiro, 16 set. 1933.

DIÁRIO DE NOTÍCIAS, Rio de Janeiro, 21 mar. 1932.

DIÁRIO DO MARANHÃO, São Luiz, 17 jun. 1902.

GAZETA DE NOTÍCIAS, Rio de Janeiro, 19 dez. 1906.

GAZETA DE NOTÍCIAS, Rio de Janeiro, 02 dez. 1910.

GAZETA DE NOTÍCIAS, Rio de Janeiro, 31 out. 1915.

GAZETA DE NOTÍCIAS, Rio de Janeiro, 24 set. 1916.

GÓIS JUNIOR, Edivaldo. Ginástica, higiene e eugenia no projeto de nação brasileira: Rio de Janeiro século XIX e início do XX. Revista Movimento, Porto Alegre, v. 19, n. 01, p. 139-159, jan./mar. 2013.

GÓIS JUNIOR, Edivaldo; HAUFFE, Mirian Kormann. A educação física e o funâmbulo: entre a arte circense e a ciência (século XIX e início do século XX). Revista Brasileira de Ciências do Esporte, Florianópolis, v. 36, n. 2, p. 547-559, abr./jun. 2014.

GINZBURG, Carlo. O nome e o como. Troca desigual e mercado historiográfico In: GINZBURG, Carlo; CASTELNUOVO, Enrico; PONI, Carlo. A Micro-história e outros ensaios. Lisboa: Difel, 1989. p. 169-178.

JORNAL DO COMÉRCIO, Rio de Janeiro, 30 mar. 1912.

LOPES, Daniel de Carvalho. Os circenses e seus saberes sobre o corpo, suas artes e sua educação: encontros e desencontros históricos entre circo e ginástica. 2020. $193 \mathrm{f}$. Tese (Doutorado em Educação) - Faculdade de Educação, Universidade de São Paulo, São Paulo, 2020.

LUCA, Tania Regina de. História do, nos e por meio dos periódicos. In: PÍNSKY, Carla Bassanezi (org.). Fontes Históricas. São Paulo: Contexto, 2008. p. 111-153.

MELO, Victor Andrade de; PERES, Fábio de Faria. A gymnastica no tempo do Império. Rio de Janeiro: 7 Letras, 2014.

MOLIER, Ernest. Le Cirque, L'Equitation et L'Athletisme. Paris: Éditione Baudiniére, 1925.

MORENO, Andrea. A propósito de Ling, da ginástica sueca e da circulação de impressos em língua portuguesa. Revista Brasileira de Ciências do Esporte, Brasília,v. 37, n. 2, p. $128-135$, mar. 2015.

MUNDO ILUSTRADO, Rio de Janeiro, 27 dez. 1958.

O GLOBO ESPORTIVO, Rio de Janeiro, 18 nov. 1939.

OLIMECHA, Raul. Pequeno Tratado de Acrobacia e Gymnastica. Campos, R J: Oficinas Graphicas Instituo Comercial, 1933. 
O TICO TICO, Rio de Janeiro, 31 jul. 1918.

PUCHTA, Diogo Rodrigues. A escolarização dos exercícios físicos e os manuais de ginástica no processo de constituição da educação física como disciplina escolar (1882-1926). 2015. 285 f. Tese (Doutorado em Educação) - Faculdade de Educação, Universidade Federal de Minas Gerais, Belo Horizonte, 2015.

REVISTA DA SEMANA, Rio de Janeiro, 07 jun. 1947.

ROMÃO, Anna Luiza Ferreira. Entre Escolas, clubs e Sociedades: as Gymnasticas tecidas por professores no Rio de Janeiro (1850 - 1900). 2016. 199 f. Dissertação (Mestrado em Educação) - Faculdade de Educação da Universidade Federal de Minas Gerais, Belo Horizonte, 2016.

ROUX, Hugues Le. Les jeux du cirque et la vie foraine. Paris: Librairie Plon/ImprimeursEditeurs, 1889.

SILVA, Erminia. Respeitável público... O circo em cena. Rio de Janeiro: FUNARTE, 2009.

SOARES, Carmen Lúcia. Educação Física: raízes europeias e Brasil. Campinas: Autores Associados, 2001.

SOARES, Carmen Lúcia. Imagens da educação no corpo: estudo a partir da ginástica francesa no século XIX. 3 ed. Campinas: Autores Associados, 2005.

STREHLY, Geoges. L'Acrobatie et les acobates. Paris: Madame S. Zlatin, 1977.

TAMAOKI, Verônica. Unidos Seremos Fortes. Notícias da primeira associação da categoria circense no Brasil - Federação Circense (1925-1938). São Paulo: Funarte, Pindorama Circus, 2007.

ZUCCA, Alberto. Acrobatica e Atletica. Milão: Editore Libraio Della Real Casa / Hoepli Manuals, 1902.

Texto recebido em 03/10/2020.

Texto aprovado em 14/01/2021. 